|| ISSN(online): 2589-8698 || ISSN(print): 2589-868X || International Journal of Medical and Biomedical Studies

Available Online at www.ijmbs.info

PubMed (National Library of Medicine ID: 101738825)

Index Copernicus Value 2018: 75.71

Original Research Article

Volume 3, Issue 5; May: 2019; Page No. 240-244

\title{
A STUDY ON HISTOPATHOLOGICAL CHANGES IN SALPINGITS, HYDROSALPINX AND TUBAL PREGNANCY
}

Dr. B.Spandana ${ }^{1}$, Dr. A.V.Jyothi, ${ }^{2}$ Dr. C.Venkata Harish ${ }^{3}$

1,2,3 - Assistant Professor, Department of Pathology, Government Medical College, Kadapa, AP.

Article Info: Received 14 April 2019; Accepted 20 May. 2019

DOI: https://doi.org/10.32553/ijmbs.v3i5.311

Corresponding Author: Dr. A.V.Jyothi, Assistant Professor, Department of Pathology, Government Medical College, Kadapa, A.P.

Conflict of interest: No conflict of interest.

\section{Abstract}

Fallopian tubes are complex structures, they represent more than conduit from ovary to endometrial cavity. They are the seats for a variety of interactions in a normally implanted pregnancy. The significance of pathogenic changes in fallopian tubes is related to infertility. Salpingitis is responsible for secondary occlusion or stenosis. The prospective study was done from June 2010 to June 2012. A total number of cases were analysed. The results obtained were subjected to analysis using Microsoft Excel spreadsheet and SPSS for statistical significance. The commonest tubal lesion is salpingitis (66). Tubal ectopic pregnancy was the second commonest condition noticed (55). The third common lesion was Hydrosalpinx

Keywords: Fallopian tubes, Infertility, Salpingitis, Kurnool

\section{Introduction}

Acute salpingitis is associated with congestion and chronic salpingitis with fibrous adhesions. ${ }^{1}$ The complication of salpingitis is the hydrosalpinx which causes the mucosal damage and causes infertility. The tuberculous salpingitis is the most common cause of occlusion and stenosis. World wide, ectopic gestation is the cause for high incidence of maternal deaths. In ectopic pregnancies, tubal rupture is common and unnoticed. ${ }^{2}$

The primary tumors of fallopian tubes are rare but the lesions can occur in postmenopausal women with non-specific symptoms. The metastasis to the tube is common than the primary tumors. The usual metastasis is from ovary, endometrium and cervix. ${ }^{3}$

It is a common surgical specimen in pathology laboratory and may be examined either as salpingectomy or tubal ligation specimen or a part of hysterectomy and or oophorectomy specimen. ${ }^{3}$ There is lack of data to describe the frequency of various histological findings in a general surgical pathology. ${ }^{1}$ The present study is undertaken in view of the disease sequelae of tubal infection, as tubal stenosis, occlusion, (granulomatous), infertility and ectopic.

\section{Objectives:}

To study the histopathological changes in Salpingits, Hydrosalpinx and Tubal pregnancy.

\section{MATERIALS AND METHODS}

The present study for a period of 2 years from JUNE 2010 to JUNE 2012 was done in the department of Pathology, Kurnool Medical College, Kurnool. During the above period fallopian tubes obtained either by tubectomy and by hysterectomy was analysed. An analysis of cases of various lesions of fallopian tubes during the above period was done. H\&E stained sections of these 780 cases were reviewed and the lesions were tabulated.

The prospective study was done from June 2010 to June 2012. A total number of cases were analysed. All specimen were fixed in $10 \%$ formalin. After gross examination, the sections at various levels were given Specimen of suspected ectopic pregnancy were also examined for the presence of embryo, placenta, haemorrhages and rupture of fallopian tube. Parrafin tissue blocks were made, the sections were stained with the Haematoxilin and Eosin. The lesions were analysed. The results obtained were subjected to analysis using Microsoft Excel spreadsheet and SPSS for statistical significance. 


\section{RESULTS:}

From June 2010 to June 2012 surgical pathology specimen were received in the department of Pathology, Kurnool Medical College, Kurnool. A total number of 780 fallopian tubal lesions giving a percentage of $10.26 \%$ among total surgical pathology specimen.

In the total number of 780 cases of fallopian tubal lesions, 596 cases were normal. The commonest lesion noted was Salpingitis (66 cases) giving a percentage of $8.5 \%$ among the total number of fallopian tubal lesions. The next common condition noticed was Ectopic pregnancy (55 cases) giving a percentage of $7.05 \%$. The third common tubal lesion noticed was Hydrosalpinx (52 case) giving a percentage of $6.7 \%$.

Table 1: Distribution of various tubal lesions encountered in the present study

\begin{tabular}{|l|l|l|l|}
\hline $\begin{array}{l}\text { Sr. } \\
\text { No. }\end{array}$ & TUBAL MORPHOLOGY & $\begin{array}{l}\text { NO. } \\
\text { OF } \\
\text { CASES }\end{array}$ & $\begin{array}{l}\text { INCIDENCE } \\
\%\end{array}$ \\
\hline A & Normal & 596 & 76.41 \\
\hline B & Abnormal & 184 & 23.58 \\
\hline 1 & SALPINGITIS & 66 & 8.46 \\
& Acute & 18 & 2.30 \\
& Chronic & 40 & 5.12 \\
& Tuberculosis & 4 & 0.51 \\
& Suture Granulomas & 4 & 0.51 \\
\hline 2 & HYDROSALPINX & 52 & 6.6 \\
\hline 3 & SALPINGITIS ISTHMICA & 04 & 0.51 \\
& NODOSA & & \\
\hline 4 & ECTOPIC PREGNANCY & 55 & 7.05 \\
\hline 5 & PARATUBAL CYSTS & 05 & 0.64 \\
\hline 6 & WALTHARD CELL NESTS & 02 & 0.25 \\
\hline 7 & TOTAL & 780 & 100.00 \\
\hline
\end{tabular}

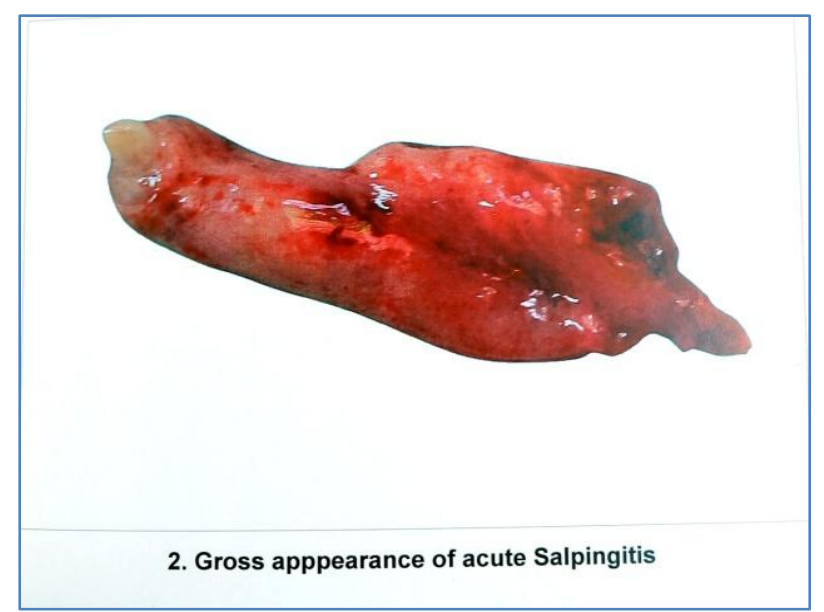

Figure 1: Gross appearance of acute salpingitis

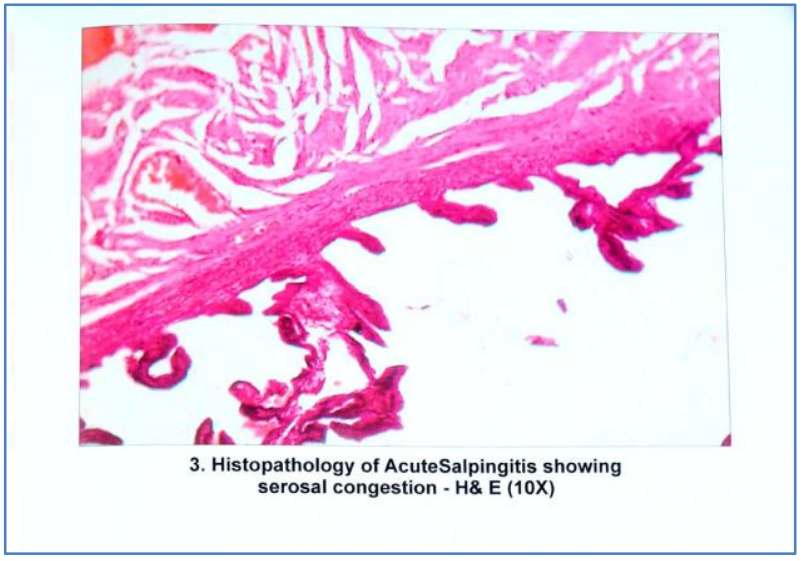

Figure 2: Histopathology of Acute Salpingitis

\section{ACUTE SALPINGITIS:}

Grossly, the tube is enlarged. Congestion of all the tubal layers. fibrinous exudate on serosal surface, focal peritonitis and abdominal and pelvic pain.

\section{CHRONIC SALPINGITIS:}

Grossly, tube is enlarged. Microscopically, thickened tubal tubal walls are noted. Fibrinous adhesions between the serosa and peritoneal surface.

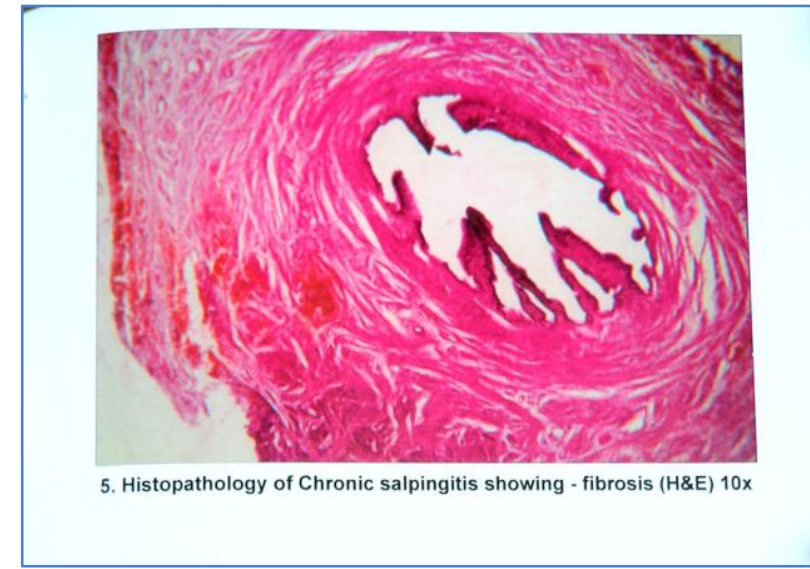

Figure 3: Histopathology of Chronic Salpingitis

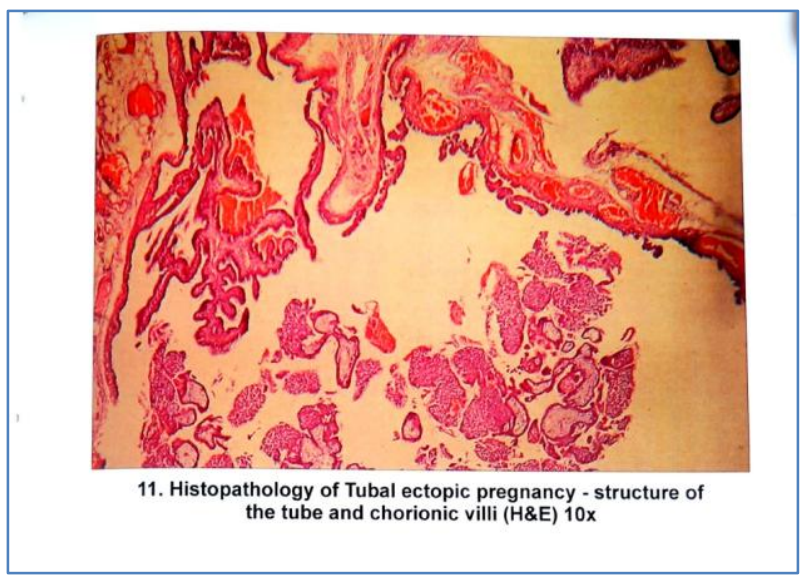

Figure 4: Histopathology of tubal pregnancy 
Table 2: Age -Wise Distribution of Tubal Lesions

\begin{tabular}{|l|l|l|l|l|l|l|l|}
\hline Sr. No. & TUBAL LESIONS & $\mathbf{2 0 - 2 5}$ & $\mathbf{2 5 - 3 0}$ & $\mathbf{3 0 - 3 5}$ & $\mathbf{3 5 - 4 0}$ & TOTAL & PERCENTAGE \\
\hline 1 & ACUTE SALPINGITIS & - & 10 & 8 & - & 18 & $9.78 \%$ \\
\hline 2 & CHRONIC SALPINGITIS & - & 28 & 12 & - & 40 & $21.73 \%$ \\
\hline 3 & $\begin{array}{l}\text { TB } \\
\text { SALPINGITIS }\end{array}$ & - & 2 & 2 & - & 4 & $2.17 \%$ \\
\hline 4 & $\begin{array}{l}\text { HYDRO } \\
\text { SALPINX }\end{array}$ & - & 28 & 14 & 10 & 52 & $28.26 \%$ \\
\hline 5 & $\begin{array}{l}\text { ECTOPIC } \\
\text { PREGNANCY }\end{array}$ & 11 & 28 & 16 & - & 55 & $29.89 \%$ \\
\hline 6 & $\begin{array}{l}\text { PARATUBAL } \\
\text { CYSTS }\end{array}$ & - & 1 & 2 & 2 & 5 & $2.71 \%$ \\
\hline 7 & $\begin{array}{l}\text { WALTHARD } \\
\text { CELLNESTS }\end{array}$ & - & - & 2 & - & 2 & $0.02 \%$ \\
\hline 8 & $\begin{array}{l}\text { SALPINGITIS } \\
\text { ISTHMICA } \\
\text { NODOSA }\end{array}$ & 2 & 3 & - & - & 5 & $2.71 \%$ \\
\hline 9 & $\begin{array}{l}\text { SUTURE } \\
\text { GRANULOMA }\end{array}$ & - & 3 & 1 & 1 & 4 & $2.17 \%$ \\
\hline
\end{tabular}

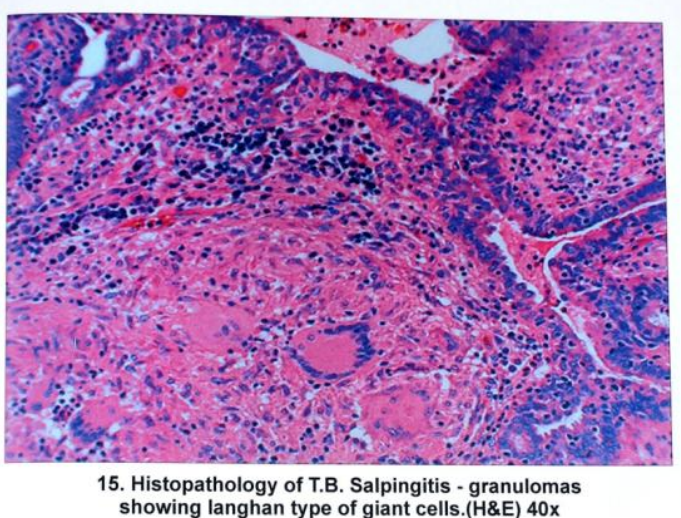

Figure 5: Histopathology of TB salphingitis

\section{TB SALPINGITIS:}

Adhesive ulcerative form: Little distention and enlargement of interstitial part. Tubercles were noted over the serosa. Adhesions were noted. Inflammatory exudative form: Tubes are markedly distended by exudates. Caseous necrosis. Walls were thin with smooth serosal surface. Evertion of the fimbiae and patency of the abdominal ostium. Tubercles were found in the septa and between epithelium lined spaces and in the mucosal folds, with minimal caseation. Presence of langhan type of giant cells. The lumen contains granules, eosinophilic debris and in advanced cases, with caseous material in the mucosal lesions.

Tubal pathological lesion was seen in $23.58 \%$ $(184 / 780)$ of the cases. In the remaining cases both the fallopian tubes were grossly and microscopically unremarkable, salpingitis (66) and hydrosalpinx constituted 52,a major group with an incidence of $184 / 780$ (23.58). Majority of the cases of acute salpingitis occurred in the age group of 25-30. Majority of cases of acute salpingitis was observed on accidental findings as tubes recognized along with uterus (abdominal hysterectomy) for treating varied gynaecological disorders.

Histological findings in acute salpingitis showed congestion while in chronic salpingitis showed fibrous adhesions. Tuberculous salpingitis was suspected on gross examination only in one case out of the four cases. Paratubal cysts (5) were seen as small benign cystic lesions. The cyst was lined by flattened epithelium noted in the age group of 30-40 years. 


\section{DISCUSSION}

During the two years, 780 cases were studied. Tubal pathology noticed in 184 cases (23.58\%). The inflammatory pathology was noted in 118.(15.12\%)Etiological subtyping of salpingitis was possible in 66 cases. The remaining 52 cases showed hydrosalpinx. Similar findings were noted by Anderson $1991{ }^{5}$ and Gompel et al $1985 .{ }^{6}$ The clinical presentation of these cases were variable.

In the present study, asymptomatic form of acute salpingitis (18) cases noted in tubes removed during post partum ligation. The process regarded as secondary to the trauma caused during delivery or intrauterine tissue necrosis. Similar findings documented by Sweet et al. ${ }^{7}$

In the present study, 18 cases of salpingitis remained clinically silent and were diagnosed as incidental finding on histopathological examination. The present study correlated with the other authors. ${ }^{8,9}$

Sweet et al documented that adherence of mucosal plicae, coalescence in the centre, luminal blocking. (clubbed tube). Healing and organization in the nonfimbriated portions of the tube with permanent bridging of the folds. In the present study, similar findings noted in chronic salpingitis. (40 cases).

The changes noted are ampullary and infundibular dilatation of the tube, obliteration of the fimbriated end. In the present study, tuberculous salpingitis was seen in four cases. One case was noted in association with adenomatous hyperplasia. The tubal lining (Moore et al 1975) suggested that such tube significance of proliferative epithelial lesions of the uterine tube. ${ }^{10}$ Three cases of tuberculous salpingitis showed serosal tubercles and with obliteration of fimbriae and ostium. These findings are correlated with the findings of (Haines 1958). ${ }^{11}$ Infertility was observed in association with acute, chronic, and tuberculous salpingitis, highlighting the possible role of inflammatory tubal pathology in causing tubal block and hence infertility. Urman et al 1992, ${ }^{12}$ had similar experience in his study

Salpingitis Isthmica Nodosa was noted in four cases. In one case it was associated with ectopic pregnancy of the tube possibly acting as a risk factor for the same. Similar were noted by Majmudar et al $1983^{13}$.

In the present study, the next major group was formed by tubal ectopic pregnancies, constituting $7.05 \%$ (55/780) of the tubal pathology. Ampulla was the commonest site for ectopic gestation, with rupture was the common outcome. Similar findings observed by Job-Spira et al $1999 .^{14}$

Inflammatory predisposing factors was noted in only in ten cases of ectopic pregnancy; hence acting as a potential risk factor. In 45 cases (out of 55) the ectopic pregnancy was diagnosed clinically. The right side tubal pregnancy was noted and correlated with the findings of (Brenner et al 1980). ${ }^{15}$

\section{CONCLUSIONS}

The total number of fallopian tubal lesion noticed in the present study were 780 . Tubal pathological lesions were noted in 184 cases. The inflammatory condition of the tube (salpingitis \& hydrosalpinx) constituted a major group.66 cases (8.46\%) of salpingitis 52 cases $(6.66 \%)$ of hydrosalpinx was noted.

\section{ACKNOWLEDGEMENTS}

We would like to thank all the study participants and the authors from where we have cited the references for publication of this article.

\section{REFERENCES}

1. Gon, S., Basu, A., Majumdar, B., Das, T., Sengupta, M., \& Ghosh, D. Spectrum of histopathological lesions in the fallopian tubes. Journal of Pathology of Nepal. 2013;3(5), 356360.

2. Lakshmi, Kasa, et al. "Histopathological study of spectrum of lesions in the fallopian tubes." Journal of Evolution of Medical and Dental Sciences. 2015;4(3):350.

3. K. V. Sathish Arora, K. Sreenivasulu, M. Janaki, Venkata Harish, Vamshaj Raja. "Study of Histomorphological Lesions of Fallopian Tubes". Journal of Evolution of Medical and Dental Sciences. 2015;4(40)6938-6943.

4. Jennifer L. Hunt amy A Lynn. Histologic features of surgically removed fallopian tubes Archives of pathology and laboratory medicine 2002, 126.951-5.

5. Anderson MC. The fallopian tube. In: Symmers WSC ed. Systemic Pathology: Female Reproductive system. London: Churchill Livingstone.1991: 241-61.

6. Gompel C, Silverberg SG. Pathology in gynaecology and Obstetrics,3rd ed. philadelphia: JB Lippincott Company, 1985; 278-305.

7. Sweet R, Draper DL, Schachter J, James J, Hadley WK, Brooks GF. Microbiology and pathogenesis 
of acute salpingitis as determined by laproscopy: What is appropriate site to sample? Am J Obstet Gynecol. 1980; 138(7 Pt 2):985-9.

8. Zdrodowska-Stefanow B. and Ostaszewska I. (2000): Chlamydia trachomatis - zakazenia u ludzi. Volumed, Wrocław, Poland.

9. Debattista J, Timms P, Allan J, Allan J. Immunopathogenesis of chlamydia trachomatis infections in women. Fertil Steril. 2003 Jun;79(6):1273-87.

10. Moore SW, Enterline HT. Significance of proliferative epit8helial lesios of the uterine tube. Obstet Gynecol 1975; 45: 385-90.

11. Haines M. Tuberculous salpingitis as seen by the pathologist and the surgeon.Am J Obstet Gynaecol(1958) 75:472-481.
12. Urman B, Gome IV, Mc Comb P et al. Mid tubal occusion: Etiology, management and outcome. Fertil Steril 1992; 57: 747-50.

13. Majumdar B, Henderson PH, Semple E. Salpinngitis isthmica nodosa: A high risk factor for tubal pregnancy. Obstet Gynecol 1983:2:7350

14. Job-Spira N, Fernandez H, Bouyer J et al. Ruptured tubal ectopic pregnancy: risk factors and reproductive outcome; results of population based study in france. Am J Obstet Gynecol 1999, 180: 938-44.

15. Brenner P F, Roy S, Mitchel D R Jr Ectopic pregnancy. A study of 300 consecutive surgically treated cases. JAMA(1980) 243-673-676 